\title{
INFORMATION AND THE PROTECTION OF ITS INVIOLABILITY IN THE CONDITIONS OF DIGITALIZATION OF THE EDUCATION IN THE UNIVERSITIES IN BULGARIA
}

\author{
Radka P. Ivanova \\ Assoc. Prof. Dr., University of Economics Varna, Bulgaria, r.ivanova@ue-varna.bg
}

\begin{abstract}
Universities receive and store a large amount of personal data of their students, subject to annual updates in relation to the annual admissions. This raises a number of issues and problems for the universities' management, among which is the protection of personal data. Digitalization in the field of education has necessitated the development and use of software products that allow work on multiple platforms in elearning environments. The platforms used by modern information systems allow access through various devices - mobile and fixed to facilitate users. However, this can lead to additional problems related to the protection of the information and personal data stored on them. In this regard, special attention is paid today to the construction of information security management systems. That is why in the field of education, where a large amount of personal information is handled, special policies are developed related to the protection of its inviolability. In addition, in connection with the current Personal Data Protection Act (PDPA) in Bulgaria, in universities special officials are also appointed to monitor compliance and resolve any cases that may arise. Ensuring the protection of information in an organization can be achieved by implementing and complying with the requirements set out in the specially created ISO 27001 . The principles presented in it should be the basis for the development of information management systems in higher education. Building such systems and making the necessary efforts for their continuous improvement can be seen as a guarantee of compliance with current legislation and regulations in this area in universities.
\end{abstract}

The purpose of this article is to characterize the essence of the ISO 27001 standard and to analyze its applicability in the field of higher education in Bulgaria to protect the integrity of personal data and information processed in higher education in the context of digitalization of education.

Keywords: digitalization, training, university, information, security, ISO 27001, Bulgaria

\section{INTRODUCTION}

The last two decades have been characterized by the acceleration of information mobility, a prerequisite for which is the high speed of development of the means and mechanisms used for the transfer of information. A number of areas of social life have undergone restructuring as a result of the widespread introduction of digital communication and various media infrastructures. This, in turn, benefits the improvement of various sectors of the economy, including education. The pandemic that has erupted since the beginning of 2020 has further complicated the conditions in which educational institutions must operate. Digitalization can generally be presented as a material process of transforming analogue clusters and information flows into digital ones. The digitalization of most of the processes has imposed new requirements and restrictions. 
Among them, the leading issue is data protection and privacy. Ensuring its reliability is a prerequisite for making the right decisions and adequacy of management actions in the specific situation.

\section{INFORMATION AND EDUCATION}

\subsection{Features of the Information}

We can point out that the information in its essence is information about various objects and phenomena of the world around us, their characteristics, states, changes; ongoing processes, etc., the presence of which makes it possible to reduce inconclusiveness and uncertainty. Historical records show that the term information has Latin origins - "informatio", which means information, explanation, and exposition - is widely used after the $30 \mathrm{~s}$ of the 20th century as a scientific term in the theory of journalism. (http://tuj.asenevtsi.com/Inf\%20sistem/I056.htm). The analysis of authors' opinions shows that in clarifying the essence of the concept of information, two main approaches are distinguished, which are opposed, namely - attributive and functional approach. According to the attributive approach, information is defined as a property of all material objects, while the functional approach focuses on the immediate functioning of systems. At the same time, we must point out that each user is looking for three main components in the information, which are: structure, meaning and value. A prerequisite for this is the fact that the use of information presupposes its orderliness, meaningfulness, and pragmatic orientation. On the other hand, information files must be well protected from malicious and improper use. This is particularly important in the age of universal digitalization and open access to much of the electronic resources handled by organizations in both the private and public sectors. Therefore, it is necessary to use appropriate methods and tools, as well as the implementation of such actions that allow the safety of stored resources, regardless of their type informational, technical, programmatic, etc. In addition to the generally accepted rules, the application of different methods in the individual organizations is important, subtracted to the development and approval of their own internal rules to ensure information security. Among the most commonly used organizational methods for information protection are security policies, data archiving systems, rules for access to various information files, including premises. The basic rule is the hierarchy of access, as well as the individual nature of this type of protection, inherent in the particular organization.

\subsection{Information in the Field of Education}

Ensuring information security is a top priority for all areas, including education. The large number of learners implies the development of an appropriate system for their identification and at the same time - confidentiality of personal data. In this regard, each school, regardless of the level it teaches - primary, secondary, higher education, uses its own way to achieve this. Universities in Bulgaria apply systems that identify students using various combinations of digits in the form of numbers, no longer store personal identification documents, such as ID cards and passports, diplomas of previous education, etc.; observe special rules for storage and archiving of the documents accompanying the students' education. The established local information security management systems must provide all this.

The storage of information implies that certain actions are taken, limited to the management of each university to define its policy related to information security; to identify and analyze security risks, as well as to predict appropriate forms of control over the security of information.

\section{THE STANDARDS: ISO 27001:2017, ISO 27002:2013 AND ISO 27701:2019}

Given the existing European and national norms, such as Regulation 679/2016 of the EU and the Personal Data Protection Act (PDPA) in Bulgaria, universities in Bulgaria publicly declare on their websites their Privacy Policy, announce the PDPA officials and their commissions, monitoring compliance with the rules, and disclose certificates they have for the information management systems.

Most of the information handled at the universities concerns the students there, who are also the major user of the services provided. The urgent need to convert to distance learning, due to the COVID-19 pandemic, has posed new challenges to higher education institutions, including finding ways to preserve information using a variety of e-learning environments. The identification of students and teachers in them required the development of special regimes and conditions for access, which are based on a certain amount of personal information. Each of the stakeholders must be convinced that the management of the respective university is taking the necessary measures, despite the changed situation and continues to comply with the existing measures. Specially developed platforms for conducting electronic examinations also require additional actions to be taken to ensure the necessary objectivity of the assessment. The efforts made by the Ministry of Education and Science (MES) in Bulgaria in 2020 led to the creation of the necessary conditions for 
training in the electronic environment, ensuring the protection of the provided information through several consecutive controls so that each of the interested parties in this process has the confidence that the misuse of personal data will not be allowed. To help the organizations, the International Organization for Standardization is also developing a special standard ISO 27001 Information Security Management Systems. It sets out the requirements for these systems related to the confidentiality, availability and integrity of information in the organizations. ISO 27001 allows the protection of both company information and information related to stakeholders with whom the organization constantly interacts. At the same time, the standard is oriented towards ensuring the continuity of the business processes taking place in the various structures, related to security management.

The information security management system is designed to preserve the integrity of sensitive information that protects people, processes, and IT systems. This is extremely important because information is an asset that adds value to the other assets and activities of each organization. The implementation of ISO 27001: 2017 is a prerequisite for ensuring the protection of available information from various threats in order to maximize the return on investment. ISO 27001: 2017 defines the relevant requirements for the maintenance and continuous improvement of the information security system, based on the process approach and the $\mathrm{E}$. Deming's cycle. The development of ISO 27001: 2017 is related to the goal of ensuring appropriate control, as well as to ensure the necessary trust between the various bodies and their partners.

On the other hand, it should be noted that ISO 27001 implies compliance with existing laws, regulations, and contractual obligations regarding the security of information and how to use it. Its successful implementation requires regular internal inspections of the information security management system, the results of which allow for its improvement. ISO 27001 is also closely related to the Personal Data Protection Act (PDPA), in connection with which special officials under this law are appointed in the universities in Bulgaria. They must monitor the strict application of the PDPA, as well as resolve cases arising in relation to it.

In addition to ISO 27001, ISO 27002 has been developed, which deals with personal information and its privacy; the selection of specific control activities related to the process of implementation of ISO 27001, application of the general ones and development of own guidelines for information security management. ISO 27002: 2013 was developed in the form of a guide and was issued in 2000, but as ISO 17799 Information Technology - Security Techniques - Code of Practice for Information Security Management (Disterer, 2013). Since 2007, the standard has been renamed ISO 27002 and with its development, good practices accentuate, which are offered in the form of methods and procedures that allow adaptation to the specifics of the different organizations.

There is another standard, also known as the Privacy Information Management System (PIMS) or as ISO 27701: 2019 Security Techniques for Information Privacy Management. It sets out a framework that controllers and processors must follow to ensure confidentiality management and the protection of personal information. ISO 27701: 2019 can be applied by any type of organization - public, private, government agencies, as well as by non-profit organizations. The requirements set in the standard allow its implementation to ensure compliance with the EU General Data Protection Regulation (GDPR), as well as all other legal provisions. Regulation 679/2016 on the protection of personal data is also the basis of the updated in 2019 PDPA in Bulgaria.

A prerequisite for the formation of such regulations is the growing interest for the protection of personal data, given the widespread threats of breach of confidentiality and the many examples of bad practices in this regard. ISO 27701: 2019 supports each organization in several main areas, namely (https://www.consejo.bg/iso-27701_11_243):

- Defining the goals of security of personal data and information;

- Ensuring the implementation of the legislation regarding the protection of personal data;

- Defining the processes for information security management;

- Increasing security in human resources management;

- Security management in relationships with suppliers;

- Providing backup copies of information and information systems;

- Development of action plans in case of an incident with the information security;

- Development of appropriate policies, procedures and other documents for defining permitted and prohibited actions when working with sensitive information and personal data, etc. 


\section{ISO 27001:2017 IN BULGARIA}

The reference made in club9000.org ${ }^{1}$ shows that by 2019 in Bulgaria there are 98 certified organizations under ISO 27001: 2017. The predominant number is the one of those operating in the field of information technology - almost $45 \%$ of all, while in the field of education there is only $3 \%$ (see Fig. 1).

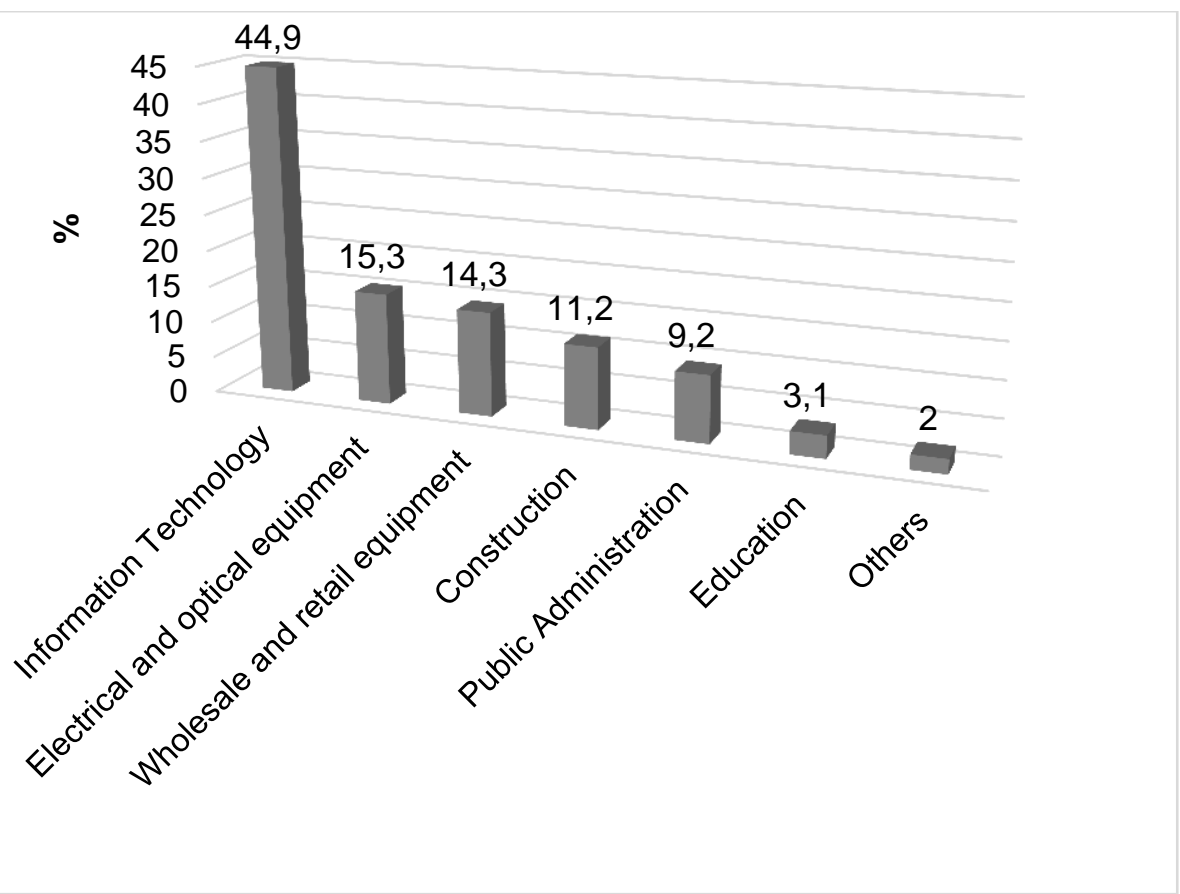

Figure 1: Distribution of the number of organizations holding certificates by sectors according to ISO 27001 in Bulgaria (as of February 25, 2019)

The data presented in this way clearly shows that ISO 27001 is not yet widely used in the field of education and work must be done towards its implementation. Given the voluntary nature of certification, on the one hand, and on the other hand, the serious financial investment to which it relates can be initiated by introducing the principles set out in ISO 27001. Compliance with them will be an appropriate step for the protection of personal data and developing policies to ensure this.

In terms of regional priority, Sofia has priority - $82.6 \%$ of the certified organizations under ISO 27001 are from the Sofia region (see Fig. 2).

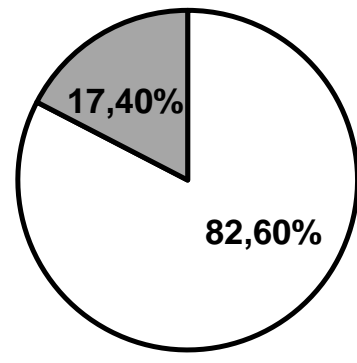

口Sofia 口Others

Figure 2: Regional distribution of the number of organizations with ISO 27001 certificates in Bulgaria (as of February 25, 2019)

\footnotetext{
${ }^{1}$ Club9000.org - Association "Club 9000" - Partner and assistant in the field of quality in Bulgaria.

2 The figure is based on data from https://www.club9000.org/bg/Statistics-Branchs.php?s=27001 [Accessed 10/10/2021]

${ }^{3}$ The figure is based on data from https://www.club9000.org/bg/Statistics-Branchs.php?s=27001 [Accessed 10/10/2021]
} 
We can associate this tendency with the better status, which characterizes the organizations from the capital region of the country. In terms of education, priority is given to educational institutions in Sofia, which receive more funding from the state, train a larger number of students, and handle a larger amount of information.

As a favorable fact we can consider that some of the organizations in Bulgaria, which have received a certificate according to ISO 27001, have other certificates - according to ISO 9001, for example. This shows their higher degree of concern about ensuring the quality of the processes taking place in their organizations and creates favorable conditions for increasing the confidence and calmness of their stakeholders.

\section{ACKNOWLEDGEMENT}

Fundamental to the activities of the organizations and institutions today is the management of information security (Nedyalkov, et al., 2017). A prerequisite for this is the fact that they face constant threats to the protection of this security. Universities handle specific information and a large amount of personal data, which must be well protected from misuse. The introduction of the position of " PDPA official" in universities is an important step in this direction. An additional advantage would be the implementation of ISO 27001 , which will ensure that a system for managing information security is established, as well as the necessary efforts are made for its continuous improvement. The development and implementation of a special privacy policy is a prerequisite to ensure that the organization concerned, and in particular the university, processes personal data conscientiously and in a transparent manner, in compliance with existing legal provisions in this regard.

\section{REFERENCE LIST}

Disterer, G. (2013). ISO/IEC 27000, 27001 and 27002 for Information Security Management. Journal of Information Security, 4, pp. 92-100. http://dx.doi.org/10.4236/jis.2013.42011

Nedyalkov, A., M. Boneva, A. Petkov. (2017). Integration of Management System in Public Organizations. IX International Scientific Conference "E-Governance and E-Communications". pp. 33-44

http://tuj.asenevtsi.com/Inf\%20sistem/I056.htm [Accessed 08/10/2021].

https://www.consejo.bg/iso-27701_11_243 [Accessed 12/10/2021].

https://www.club9000.org/bg/Statistics-Branchs.php?s=27001 [Accessed 10/10/2021] 